\title{
THE IMPACT OF FAST TRACK CONSTRUCTION AND CONSTRUCTION MANAGEMENT ON SUBCONTRACTORS
}

\author{
William R. SQUires, III \\ and Michael J. MURPhY*
}

I

INTRODUCTION

In response to such factors as the high cost of financing and runaway inflation of construction costs, several new approaches have been developed in the construction industry to compress the construction time involved in a particular project. Two of these approaches are fast track construction and construction management. This article examines the impact of these new approaches on subcontractors. Because there is little empirical data and not much case law concerning these new approaches, very little hard evidence of the impact of these new approaches exists. Experience with fast track construction and construction management to date, however, suggests that neither approach creates any intrinsically new problems for the construction industry. Rather, these approaches merely add new players (or change the names of some of the existing players), change the context in which more traditional problems arise, and possibly increase the volume of certain types of problems.

The first issue that must be addressed is definitional: Exactly what are fast track construction and construction management? The remainder of this article discusses some of the problems affecting subcontractors that arise under the two processes. The article also discusses how some of these problems can be minimized, both at the contract negotiation and drafting stages, and in the field.

\section{II}

\section{Definitional Problems}

The terms fast track construction and construction management appear throughout the literature and, on occasion, in the case law, but it is readily

Copyright $\mathcal{C} 1983$ by Law and Contemporary Problems

* Attorneys, Davis, Wright, Todd, Riese \& Jones, Seattle, Washington. 
apparent from even a cursory review of the literature' and case law ${ }^{2}$ that no two authors define their terms in the same manner. Thus, before any analysis of the impact of these two approaches can be discussed, the terms themselves must be defined.

Both fast track construction and construction management are processes. ${ }^{3}$ They are means of accomplishing an end, namely the completion of a particular construction project. The fast track process has been defined as "a method of construction by which actual construction is commenced prior to the completion of all design, planning, bidding and subcontracting stages in order to alleviate the effects of inflation."4 Although this general definition is accurate, it tells little about the details of the process.

A somewhat more detailed description found in the literature states that under the fast track approach the owner outlines for the architect the general criteria for the project. The architect then prepares, in varying degrees of detail, basic design documents, schematics, heating, ventilation and air conditioning, electrical, and preliminary structural drawings. From these incomplete drawings, the selected contractor (or the bidding contractors) estimates the cost of construction and then proceeds toward firm negotiations or bidding. The contract with the general contractor can then take any number of forms, including a lump sum or guaranteed maximum cost arrangement, a cost-plus arrangement, or a phased combination of the two. ${ }^{5}$

One definitional issue that has arisen is whether fast track construction requires the use of a construction manager (CM) and the elimination of the general contractor. The majority view reflected in the standard literature indicates that fast track construction methods can be utilized through either a general contractor, $\mathrm{CM}$, or both. It is the opinion of some in the industry, however, that true fast track construction should not include a general contractor but requires the use of a CM. ${ }^{6}$ As will be discussed below in more detail, the presence of a CM in lieu of or

1. See, e.g., J. Adrian, CM: The Construction Management Process 208-26 (1981); G. Henry, Time, Cost and Architecture 43-44 (1975); F. Merritt, Building Construction HandboOk §§ 120 to 21 (3d ed. 1975); Cushman, Meyers \& Sapers, Preparation of the Construction Agreement from the Owner's Viezpoint, in Businessman's Guide to Construction 175, 220-26, 276 (1980); Meyers, The New Contractual Arrangements, in 1 ConstruCtion ConTRACTs 1981, at 15, 23-25, $197-98$ (1981) ("There is no universally accepted definition in usage for "fast track" and, in turn, a great deal of confusion seems to accompany the use of this catchy jargon.").

2. See, e.g., City Stores Co. v. Gervais F. Favrot Co., 359 So. 2d 1031, 1032 (La. App. 1978); Meathe v. State Univ. Constr. Fund, 65 A.D.2d 49, 50, 410 N.Y.S.2d 702, 703 (1978); Mongiovi v. Doerner, 24 Or. App. 639, 644, 546 P.2d 1110, 1113 (1976); Hughes v. Edwards, 265 S.C. 529, 544, 220 S.E.2d 231, 238 (1975).

3. See Meyers, supra note 1, at 22-23, (fast track and construction management are new forms of construction agreements). But see J. ADRIAN, supra note 1 , at 1 (construction management is a process, but fast track is merely a tool of construction management firms).

4. Meathe v. State Univ. Constr. Fund, 65 A.D.2d 49, 50, 410 N.Y.S.2d 702, 703 (1978).

5. See Cushman, Meyers \& Sapers, supra note 1, at 220; Meyers, supra note 1, at 23-25.

6. See Mongiovi v. Doerner, 24 Or. App. 639, 644, 546 P.2d 1110, 1113 (1976) (quoting testimony of witness regarding construction management and fast track construction methods). See generally J. ADRIAN, supra note 1, at 1, 208 (suggesting fast track is only a tool or technique of construction management firms, not necessarily a separate process). 
in addition to a general contractor may create certain problems regarding owner authorization or ratification of certain extra work or changes.

The second definitional issue related to the fast track method is the "completeness" of the plans and specifications. The generally accepted rule appears to be that if construction begins with less than half of the plans and specifications complete, the project can be considered a fast track project. This statement may be accurate with respect to a fast track project involving a general contractor. That is, the general contractor may bid on the project when the plans and specifications are less than half complete. This general statement, however, has little relevance to subcontractors. Under the fast track approach, all subcontracts are not necessarily let at the same time or even at approximately the same time. The very nature of the process is such that the contracts are often let as a particular phase of the project is ready to begin. This is true whether a general contractor or a CM is involved. To say that a fast track project begins when as little as twenty to thirty percent of the plans and specifications are complete is therefore irrelevant to any particular subcontractor. The relevant issue to a subcontractor is the relative completeness of plans and specifications for $i t s$ phase of a particular project at the time its subcontract is negotiated or bid.

Most practitioners in the field, including both construction companies doing management work and firms doing only construction management work, try to make a practice of offering subcontractor bid packages only when the plans and specifications for that particular package are nearly complete. For example, although the plans and specifications for the entire project may be only thirty percent complete when subcontractor bids are solicited for the initial work, such as foundation and site work, the plans and specifications for the foundation and site work should be at least $80 \%$ complete. There are, of course, exceptions to this preferred approach. The percentages will depend on the circumstances of a particular project and the quality of the general contractor or CM, but the important point is that a general description of fast track construction that refers to contracts being let when the plans are only twenty to thirty percent complete is not necessarily accurate with respect to individual subcontractors. This point is not adequately conveyed in the literature, and the limited discussions of fast track construction in the case law suggest that the courts may not understand the point either.

The definition of construction management is even more elusive. The organizational structure of the construction management process can vary considerably. It may or may not include a general contractor. If there is no general contractor, the CM may or may not take on the role of a general contractor, doing some of the work itself. More importantly, the nature of a subcontractor's relationship to the project owner can vary considerably. If a general contractor is involved, the subcontractors will undoubtedly have their contractual relationships with the general contractor. If there is no general contractor, the subcontractors (more appropriately called prime contractors under these circumstances) will most likely have direct contractual relationships with the project owner. In some instances, the sub/prime contractors might have a direct contract with the CM. This latter vari- 
ation makes the CM more like a general contractor than a mere provider of construction management services. ${ }^{7}$

As this brief discussion indicates, neither the fast track construction process nor the construction management process is well-defined. This point is important because the variability of the respective definitions or descriptions may have a significant impact on the subcontractor.

\section{III}

\section{IMPACT OF The Fast TRACK Process on Subcontractors}

The fast track process does not appear to create any new problems for subcontractors. It does, however, contain within it the possibility of increasing the volume of certain types of existing problems.

Although it is the stated policy of many if not all general contractors or CMs engaged in fast track construction to let the subcontracts or specialty prime contracts only when the respective bid packages are nearly complete, the nature of the fast track process may create pressures for letting individual specialty or prime contracts before the packages are as complete as the general contractor or CM would like. Similarly, depending on the particular project and the design, it may be impossible to wait until the respective specialty or prime contract bid packages are complete before soliciting bids. As a result, certain specialty or prime contracts on a particular project may be based on substantially incomplete plans and specifications. Consequently, there is likely to be a greater number of disputes over change orders. ${ }^{8}$ As one author has stated, "There is also an almost built-in area for costly litigation when it comes to determining whether or not the completed drawings represent a change in scope from the original preliminary drawings or simply represent completion of the original drawings . . . ."9

Additionally, as the plans and specifications for a fast track project are completed and/or revised there is a greater likelihood of scheduling problems and therefore an increased chance of claims for damages for delay. ${ }^{10}$ Further, a subcontractor or prime contractor may perform work that is not specifically provided for in the plans but that the subcontractor legitimately believes is implicit if the plans and specifications are to be carried out and the contract as a whole is to be fulfilled. As with change orders, this can lead to disputes about whether authori-

7. See J. Adrian, supra note 1, at 21; Cushman, Meyers \& Sapers, supra note 1, at 236-37; Meyers, supra note 1 , at 121-25.

8. See J. AdRiAn, supra note 1, at 208 ("there is more potential for change orders associated with phasing relative to nonphasing").

9. Meyers, supra note 1 , at 198.

10. Cf. Housing Auth. of Texarkana v. E.W. Johnson Constr. Co., 264 Ark. 523, 573 S.W.2d 316 (1978) (owner may be liable for damages resulting from delays caused by defective plans and specifications; not a fast track project).

Under Washington law, which the authors are most familiar with, "no damages for delay" clauses in consiruction contracts are unenforceable. See WASH. REv. CODE ANN. \$ 4.24.360 (Cum. Supp. 1982). The Washington Supreme Court and Courts of Appeals precipitated this legislative change in the law. See Nelse Mortensen \& Co. v. Group Health Coop., 90 Wash. 2d 843, 586 P.2d 469 (1978) (adopting opinion of appellate court), afg 17 Wash. App. 703, 566 P.2d 560 (1977); Seattle v. Dyad Constr., Inc., 17 Wash. App. 507, 565 P.2d 423 (1977). 
zation was necessary, and, if so, whether the extra work was expressly or implicitly authorized by the owner.

Finally, if plans and specifications for subcontract work are incomplete, it is possible that a specific item of work may not be provided for and consequently go unnoticed because one subcontractor believes that the particular item has been or should be completed by another overlapping subcontractor, and the other subcontractor believes that the first subcontractor is responsible. As one author points out, "The more the construction phase of a project is broken into individual packages, the more likelihood there is that needed construction work or responsibilities will be omitted in defining the contract packages." 11

There is little case law on the specific problems identified above; but in many instances, there is case authority on general construction law that suggests that such problems are likely to arise under the fast track process.

With respect to the increased likelihood of change order disputes, there is at least one fast track construction case that indicates the problem does exist. In City Stores Co. v. Gervais F. Favrot Co.,$^{12}$ a contractor sought to recover for additional work. The contractor claimed that later drawings and specifications contained numerous changes, additions, and deletions, presumably not foreseeable by the parties. ${ }^{13}$

Although the case was decided on procedural grounds relating to a previous arbitration, the underlying facts of the case clearly show the risks for both general contractors and subcontractors under the fast track process. The more incomplete the plans and specifications are in general or with respect to any particular subcontract or prime contract, the greater the likelihood that there will be a significant volume of change orders and change order disputes.

The problem of incomplete plans and specifications and the consequential high volume of change orders was also examined in Daugherty Co. v. Kimberly-Clark Corp. ${ }^{14}$ The Daugherty case did not involve a fast track construction project, but it demonstrated the consequences of a high volume of change orders. The Daugherty case involved a suit brought by the general contractor against the owner concerning the construction of a paper mill. At trial, one of the general contractor's key witnesses testified that the project was poorly engineered and designed and that the poor engineering resulted in "enormous changes ordered by defendants." 15 The court stated that "there was evidence that it was inconceivable that anyone could expect a contractor to anticipate the many changes in the drawings ... [and that] [t]he final drawings differed markedly from those offered for bid purposes, increasing the costs substantially." 16

11. J. ADRIAN, supra note 1 , at 219 . The author goes on to state that such unintentional omissions may result in delays and costly change orders for the project owner. Id. at 219-20. What the author does not discuss, however, is that such unintentional oversights or omissions can result in costly disputes and potentially serious losses for the subcontractors who the owner will certainly allege were responsible for the alleged omissions or oversights.

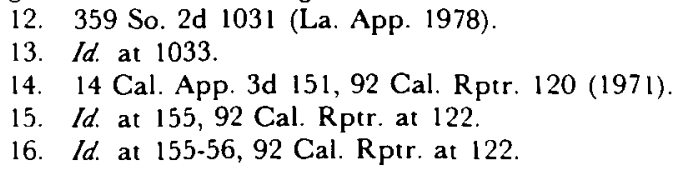


The legal question raised by the high number of changes was "whether the contract had been abandoned by the parties." 17 If the contract was in fact abandoned by the parties, then the plaintiff might be entitled to recover under the theory of quantum meruit rather than under the terms of the contract. The trial court had granted summary judgment in favor of the defendant. The appellate court reversed the trial court, finding that material issues of fact were in dispute regarding whether the original contract, and in particular the change order procedure, had been abandoned. ${ }^{18}$

The risk here is apparent. The high volume of change orders resulting from "completion" and "revision" of the original plans and specifications in a fast track project may lead a court to conclude that the original contract was abandoned in its entirety and therefore to award damages to the sub/prime contractor(s) on the basis of quantum meruit.

The Daugherty case suggests another related and possibly undesirable consequence: the increased possibility of a waiver of the change order procedure. ${ }^{19}$ With an increased volume of change orders resulting from incomplete plans and specifications, the owner and its sub/prime contractors in a fast track project may be tempted to shortcut the procedures set forth in the contract and handle change orders informally to avoid delays and paperwork inherent in the change process. Under standard contract provisions a subcontractor may lose its right to recover additional compensation for changes ordered by the owner or general contractor if it fails to follow procedures set forth in the contract. There is ample authority, however, for allowing subcontractors to recover even though they have not followed the specific contractual procedures if it can be established that the owner or general contractor waived, either expressly or by conduct, the change order provisions of the contract. ${ }^{20}$

There is no assurance, however, that a court or arbitrator will find that the owner or general contractor has waived the contract change order procedure. If no waiver is found, a sub/prime contractor may face a substantial loss for work it legitimately believed was ordered by the owner. As with abandonment, the basic problem here is uncertainty for both the sub/prime contractors and the owner or general contractor.

Subcontractors, on the other hand, may derive a certain benefit from a higher volume of change orders. In a highly complex project (arguably not suitable for a fast track construction in the first place), the high volume of change orders may

17. Id. at 156,92 Cal. Rptr. at 122 .

18. Id. at 157-59, 92 Cal. Rptr. at 124-25.

19. There is a distinction between abandonment of the contract in its entirety, as alluded to in Daugherty, and waiver of the contractual change order procedures. The former (abandonment) could conceivably result in a quantum meruit recovery for a general contractor or subcontractor for the entire project. The latter (waiver) is a means of allowing a general contractor or subcontractor to actually recover for additional or changed work even though the contractual provisions regarding requests and approval of such work and payments therefore were not complied with. Recovery under this latter theory may also be based on quantum meruit.

20. Southern Md. Hosp. Center v. Edward M. Crough, Inc., 48 Md. App. 401, 405, 409-10, 427 A.2d 1051, 1054, 1056 (Ct. Spec. App. 1981); Jarosz v. Caesar Realty, Inc., 53 Mich. App. 402, 405, 220 N.W.2d 191,193 (1974). 
give the subcontractor an opportunity to recover possibly excessive profit from the owner. Although it is frequently said that no one ever grew prosperous from change orders, it might be more difficult and more costly to terminate a particular subcontractor in the middle of a project and find a replacement (and also litigate any claims by the subcontractor for breach of contract) than it would be to pay the existing subcontractor an unreasonable profit on the change orders. Although there is no hard evidence that this in fact happens, it is a widely held view that some firms do make (and count on making) a substantial profit on changes.

The second major consequence of incomplete plans and specifications is disruption of scheduling. As the plans and specifications for a particular subcontractor on the project are completed and/or revised, that subcontractor's schedule will undoubtedly be affected. This impact will likely modify the schedules of other subcontractors. This domino effect, if not properly coordinated by the general contractor or CM, could result in claims for damages for delay. If the project involves a general contractor, the subcontractor's claims will normally be initially directed at the general contractor. If the project involves a CM and multiple prime contractors, the damages for delay claims will most likely be initially directed at the owner. As with the change order problems discussed above, there is no hard evidence that this has become a problem in fast track projects, but the possibility appears to be in the background.

The third area of impact relates to "extras." If the plans and specifications are incomplete, there is a greater likelihood that a diligent subcontractor will perform work that is not expressly provided for in the plans and specifications, but which the subcontractor believes is reasonably necessary to carry out the plans and specifications as provided. As a general rule, the owner must authorize extras. ${ }^{21}$ If in subsequent litigation the sub/prime contractor cannot prove that the owner authorized the extra services and that such services were reimbursable under the contract, the contractor may suffer a substantial loss. ${ }^{22}$

The final problem is a bit unusual but not unheard of. In Grinnell Fire Protection Systems Co. v. W.C. Ealy E Assoc., ${ }^{23}$ a subcontractor sued a general contractor to recover the unpaid balance due on a contract to install a sprinkler system. The general contractor counterclaimed for the alleged cost of completing the subcontract and for damages for delay. The general contractor alleged that the subcontractor had failed to install the necessary water-pumping equipment to produce the requisite supply, flow, and pressure for the sprinkler system. ${ }^{24}$ The court determined that installation of the pump was not within the scope of the subcontractor's contract and awarded damages accordingly, denying recovery on the general contractor's counterclaim. ${ }^{25}$

21. See, e.g., Brown v. Maryland Casualty Co., 246 Ark. 1074, 1084-85, 442 S.W.2d 187, 193 (1969); R \& R Constr. Co. v. Junior College Dist. No. 529, Olney, 55 Ill. App. 3d 115, 118, 370 N.E.2d 599, 602 (1977); Castle Concrete Co. v. Fleetwood Assoc., Inc., 131 Ill. App. 2d 289, 293-94, 268 N.E.2d 474, 476-77 (1971).

22. See Meathe v. State Univ. Constr. Fund, 65 A.D.2d 49, 53, 410 N.Y.S.2d 702, 705 (1978).

23. 552 S.W.2d 747 (Tenn. 1977) (project was "design-build" not fast track).

24. Id. at $748-50$.

25. Id. at $750-51$. 
The construction project was referred to by the court as a "design and build" contract under which each particular subcontractor or prime contractor was required to do the necessary engineering and design for its particular portion of the work. The basic problem on the project was that no one was responsible for overall engineering. ${ }^{26}$ In other words, each individual subcontractor engineered, designed, and completed its share of the project, but there was a breakdown in coordination of this process. As the court pointed out,

[T] he problem which did arise was inherent in the nature of the method adopted for design and construction. The omission to anticipate the need for a pump is attributable to no one in particular, but to the method of planning which afforded the opportunity for an omission in assignment of responsibility. 27

The same problem could occur in a fast track project. If the plans and specifications for several subcontractors, whose work should interface or overlap at various points, are incomplete, there is an increased likelihood that important elements of the project may be delegated to no one. If there is tight overall control by either a general contractor or a CM, the problem is less likely to occur, ${ }^{28}$ but the risk is still present.

These problems are not unique to the fast track construction process. They are essentially the same or similar to problems that arise under the more traditional methods. One unique problem that has come up in fast track construction is the impact of state expenditure or bond issue limits. The problem, in brief, is that statutory or voter-approved state or local government expenditure limits, or limits on the issuance of general obligation or other types of bonds, may effectively terminate ongoing fast track construction projects. The problem arises because not all subcontracts are let at or near the beginning of the project. They are let as the project progresses. In the case of Hughes $v$. Edward, ${ }^{29}$ the Supreme Court of South Carolina was forced to consider the effect of a provision of the state's General Appropriations Act that limited debt service requirements for state general obligation bonds to five percent of the state's general fund revenue for the preceding fiscal year. The Act, in effect, precluded the state from issuing bonds above a certain level. An exception to the Act permitted issuance of bonds in excess of the ceiling when contracts for a particular project had been let prior to the date the Act went into effect. ${ }^{30}$

One issue faced by the court was whether the limitation applied to a fast track construction project involving a university building. The project had been underway for several years but was not complete and, most importantly, all of the contracts had not been let at the time the Act went into effect. ${ }^{31}$

The court held that the Act did apply, finding that there was no exception for the fast track approach and that the Act meant what it said: the exception was available only to contracts that had already been let. The court indicated, how-

\footnotetext{
26. Id.

27. Id. at 751; see also J. ADRIAN, supra note 1, at 219-20.

28. See generally J. ADRIAN, supra note 1 , at 208-26.

29. 265 S.C. $529,544,220$ S.E. 2 d 231, 238 (1975).

30. Id. at $533,539,220$ S.E. $2 \mathrm{~d}$ at $233,236$.

31. Id. at 544,220 S.E. $2 d$ at 238 .
} 
ever, that the result was not as onerous as it might appear because there were other methods by which the state could fund the remaining work. ${ }^{32}$

The problem presented in the Hughes case appears to be unique. In view of developments such as Proposition 13 in California, ${ }^{33}$ similar propositions in other states, and Initiative 394 in the State of Washington, ${ }^{34}$ however, the financing for other government-funded fast track construction projects could be impaired, requiring the relevant entities to seek alternative funding. Such funding may not be available if the scope of the project is prohibitively large.

The fundamental theme running throughout the problems identified, other than those related to the funding of public or quasi-public work projects, is foreseeability. When plans and specifications are incomplete it is foreseeable that there will be changes and revisions, but the extent and volume of those changes and revisions are not foreseeable. The same is true with respect to scheduling. It is obvious that scheduling will need to be adjusted to accommodate revision and completion of the plans and specifications, but at the outset the nature and extent of the scheduling problem will not be known. The problem with respect to extra work is similar, but the risks to the subcontractor may not be as great because the subcontractor, at least theoretically, has more control over required extra work. Finally, lack of coordination between subcontractors is always a problem and is therefore always foreseeable to a certain extent. But that response begs the question. The fundamental issue, and the issue with respect to all these problems, is how foreseeable these problems are and how the risk of these problems should be allocated.

Contract negotiation and drafting is, among other things, the art of risk allocation and avoidance. Construction contracts are possibly the best example of this aspect of contract law. The various contracts relating to a particular project attempt to allocate both foreseeable and, to a degree, unforeseeable risks among the parties, from the owner through the material suppliers for the sub-subcontractors and beyond. ${ }^{35}$ The starting point for providing solutions to the problems identified above therefore lies in the contract documents themselves.

The effect of the unforeseen variables can be ameliorated, if not avoided in their entirety, through careful drafting of contract and subcontract documents. Too often, contractors are expected to build fast track projects under contract documents better suited to fully designed, firm price jobs. Similarly, subcontract work packages are often let under the general contractor's standard subcontract agreement. While most of these forms contain as much protection for the general contractor as its lawyers can comfortably place in print, they rarely constitute realistic efforts to deal with the heightened exposure of both general contractor and subcontractor to the change order, extra work, and scheduling problems attendant upon a fast track project.

\footnotetext{
32. Id.

33. Cal. Const. art. XIII

34. Initiative 394, 1981 Wash. Legis. Serv. 1397 (West) (to be codified at Wash. REv. CoDE ANN. $\S 80.52 .010-.080)$.

35. See Pratt, Contracts and Economic Uncertainty, LAW \& ContemP. Probs. Winter 1982, at 169.
} 
Every party that undertakes a role in a fast track project should know what it is getting into. The contract documents should, therefore, specify the extent to which design is complete, not just for the project as a whole, but for individual subcontractor work packages as well. The contracts should be designed to encourage the flow of information from the owner and its design team down the contractual chain and vice versa. Interferences, design errors, gaps, and the like are often discovered either in the field or in the offices of a subcontractor's engineer. Contract mechanisms should be designed to speedily carry the discovery of such problems to the attention of those whose responsibility it is to solve them. Similar mechanisms should be established to communicate the solution to those who will incorporate it into the work.

The contractual mechanisms, however, must be practical and useful in the field. A highly complex and detailed set of procedures, apparently covering every conceivable permutation, may be a drafter's masterpiece. If the procedures are ignored in the field, however, the drafter's work will be for naught. The courts will again be left to apply the doctrines of waiver and abandonment, and thereby determine upon whom the loss will fall.

Changes, extras, and delays mean money to both generals and subcontractors. On projects for which a large volume of changes are anticipated, rapid and clear channels of communication should be supplemented by rapid change and claim processing procedures. On large projects, these procedures should include some provision for interim payments on acknowledged changes. Such procedures will undoubtedly increase field and home office overhead expense. Without such procedures, however, contractors may find themselves investing large portions of their working capital in unnegotiated change orders.

Owners embarking upon fast track projects should recognize that they remain responsible for timely completion of design. If, as sometimes happens, design completion is neither timely nor truly complete, the owner should not expect its contractors to assume the risk of loss, and the contract documents should so provide. Similarly, general contractors should not expect their subcontractors to have any greater luck in hitting a moving target than they have. Both prime and subcontractors can avoid some attempts at undue risk-shifting by taking exception to proposed contract language. The management flexibility necessary to successfully carry a fast track project to completion, however, should not depend upon the parties' relative bargaining strength or sophistication. Fast track construction, by its very nature, is a cooperative process. If the actors in the process are forced to spend inordinate resources on protecting themselves against liability, they will have difficulty mustering either the will or the time to make the project work.

\section{IV}

\section{Impact of Construction Management Process on SUBCONTRACTORS}

The most important problem of construction management from the point of view of the subcontractor is the addition of an actor whose legal relationship to other actors involved remains unclear. 
A CM may have various duties and responsibilities under its contract with the owner. The construction phase duties of a CM may include development, monitoring and revision of the construction schedule, supervision of the work, inspection and approval of the work, coordination of the various subcontractors or prime contractors, monitoring compliance with various job safety and employment statutes, processing of progress payments, and processing of change orders. ${ }^{36}$ These tasks are neither particularly new nor innovative. They are the same tasks that a general contractor performs under more traditional contracting methods. The critical difference between the traditional method and the construction management approach, however, is that under the construction management approach the tasks are undertaken by a party with whom the various sub/prime contractors generally have no specific contractual relationship-a party who, while having various work management responsibilities, owes its principal allegiance to the owner.

The ambiguous legal relationship between the subcontractor and the CM has several practical consequences. First, it raises the question of who is in charge. ${ }^{37}$ This inherent organizational problem can be further complicated if the project utilizes a general contractor with whom the subcontractors actually have their contractual relationships.

This problem, however, can probably be minimized by clear delineation in the contract documents of the chain of command and by careful adherence to the chain once established. Particular discipline must be practiced by the CM, who must overcome the natural tendency to deal directly with affected subcontractors to resolve problems.

A more concrete problem relates to change orders and extra work. Although the CM is generally viewed as an agent of the owner and is generally the actor responsible for processing change orders, there is no suggestion in the literature that the standard change order procedure, which requires the owner to execute the change orders, should be varied. Likewise, the standard form contracts suggested for use in construction management projects do not change the traditional requirement that the owner approve all changes. ${ }^{38}$

One of the claimed advantages of the construction management approach from the owner's perspective, however, is that it puts an entity in charge of the project that has similar if not identical interests to those of the project owner. This arrangement allows the owner to have greater control over the project, while at the same time allowing it to limit its actual involvement in the project's daily affairs.

Because an owner may use a CM to limit its direct involvement in the construction project, the sub/prime contractors may be forced to rely on the words and actions of the CM with respect to daily processing and approval of change orders and extra work. This working arrangement may be more efficient than following the contract procedure for owner approval. In the event of subsequent

36. See J. Adrian, supra note 1, at 54-64; Ball, Selecting Your Builder, in Busintssman's G('II): T() Construction 149, 158-60 (1980).

37. See J. ADRIAN, supra note 1 , at 20.

38. See Cushman, Meyers \& Sapers, supra note 1, at 277 
change order disputes or litigation, however, a subcontractor may be forced to rely on a waiver theory. The only evidence of waiver of the formal change order procedure may be the words and actions of the CM. This situation could create rather serious risks for a subcontractor. At present there is no case law regarding the authority of a CM, and the literature acknowledges that its authority and legal responsibility are uncertain. One solution might be to define the precise authority of the construction manager in both the owner-construction manager contract and the owner-sub/prime contractor contracts. This is no solution for the subcontractors, however, because it might only make utilization of the waiver doctrine more difficult.

This problem may be compounded in projects that also utilize the fast track process because, as discussed above, there is likely to be a greater volume of changes and modifications of the plans and specifications with the attendant temptation to rely on informal methods. Reliance on such informal methods by a subcontractor could result in a substantial loss if the CM is found not to have the authority to bind the owner.

As with the chain of command problem, the best solution is for the subcontractor to avoid slipping into an informal procedure and, instead, to adhere to the procedures set forth in the contract documents. If the owner, the CM, or the general contractor wishes to alter or streamline the various procedures, the contract documents may be modified accordingly, but a subcontractor should not rely on the future good will of either the general contractor or the courts.

An additional practical consequence of the use of the construction management process, in particular the variation that does not utilize a general contractor, is the resulting requirement that all subcontractors be bonded. ${ }^{39}$ The consequence from the owner's standpoint is that many unbondable specialty contractors will not be able to bid on the project, possibly leading to a higher project cost ${ }^{+0}$ Viewed from the subcontractor's perspective, the primary consequence is the same-loss of bidders. The loss of competition from unbonded specialty contractors, however, may be permanent in that certain subcontractors may be forced out of business as a result of being locked out of a particular segment of the market. This is obviously an undesirable consequence for any specialty contractor other than those few who would benefit from the loss of competition and the gradual monopolization of specialty trades.

\section{$\mathrm{V}$ \\ CONCLUSION}

Fast track construction and construction management may provide excellent solutions to the problems they were designed to address. Neither process, however, is a cure-all for construction industry problems, and from the standpoint of the subcontractor, these new processes may create more difficulties than they solve.

For the owner, for instance, the use of a construction manager may facilitate

39. See J. ADRIAN, supra note 1 , at $36-37$

40. Id. 
construction of a complicated project with a minimum of direct involvement. For the subcontractor, however, the CM may merely be one more cook stirring the broth.

Similarly, fast track design may permit an owner to significantly reduce the amount of time which it might otherwise take to design and build a large, complex project. For the subcontractor, however, incomplete design may mean only delays, changes, and lost profits.

There exists no panacea for the resolution of these conflicts. If, however, owners, prime contractors, and CMs choose from the outset flexible contract terms pertinent to the specific type of project; if they recognize the subcontractor's need for and entitlement to clear, prompt direction; if they avoid the temptation to shift inordinate risk to parties who, in many instances, are least able to bear it; then the effect of the fast track and construction management processes upon the subcontractor will be minimized. 
